\title{
Who Is Afraid of Skilled Migrants From Europe? Exploring Support for Immigration Control in Switzerland
}

\author{
Claudia Diehl* ${ }^{*}$ Thomas Hinz ${ }^{*}$, and Katrin Auspurg**
}

\begin{abstract}
The paper analyses the role of economic and cultural threat in exploring support for immigration control in Switzerland. A factorial survey experiment enables us to look into different migrant characteristics. Results show more support for immigration control for Eastern Europeans and low-skilled migrants. However, German migrants do not gain acceptance due to being highly skilled, and their willingness to adapt culturally is crucial for native Swiss with a high level of national pride.

Keywords: immigration control, Switzerland, cultural threat, economic threat, factorial survey experiment
\end{abstract}

\section{Wer hat Angst vor hochgebildeten Zuwanderern? Erklärungsversuche für die Unterstützung einer Einwanderungskontrolle in der Schweiz}

Zusammenfassung: Der Artikel beschäftigt sich mit der Bedeutung ökonomischer und kultureller Bedrohung für die Forderung nach Einwanderungskontrolle in der Schweiz. Anhand eines faktoriellen Surveyexperiments analysieren wir die Bedeutung unterschiedlicher Merkmale von Einwanderern. Zuzugsbegrenzungen werden v. a. für Osteuropäer und gering qualifizierte Einwanderer gefordert. Deutsche profitieren aber nicht von höherer Bildung, zudem spielt bei ihnen die Bereitschaft zur kulturellen Anpassung eine entscheidende Rolle.

Schlüsselwörter: Zuwanderungsbegrenzung, Schweiz, kulturelle Bedrohung, ökonomische Bedrohung, faktorielles Surveyexperiment

\section{Qui craint les migrants qualifiés d'Europe? Une exploration de la volonté de régulation de l'immigration en Suisse}

Résumé: Cet article analyse le rôle de la menace économique et culturelle dans la volonté de réguler l'immigration en Suisse. Notre sondage expérimental factoriel démontre que la volonté de réguler l'immigration est particulièrement forte à l'égard des migrants de l'Europe de l'Est et des les migrants avec un niveau de qualification bas. Le haut niveau de qualification des migrants allemands ne joue toutefois pas en faveur de leur acceptation et leur volonté à s'adapter à la culture suisse est considérée comme cruciale.

Mots-clés: contrôle de l'immigration, Suisse, menace culturelle, menace économique, sondage expérimental factoriel

Universität Konstanz, Fachbereich Geschichte und Soziologie, D-78457 Konstanz, claudia.diehl@uni-konstanz.de, thomas.hinz@uni-konstanz.de.

** Ludwig-Maximilians-Universität München, Institut für Soziologie, D-80801 München, katrin.auspurg@lmu.de. 


\section{Introduction ${ }^{1}$}

In February 2014, Swiss voters approved by a narrow margin of less than a 1 percentage point a popular initiative supported by the SVP (Swiss People's Party) that aimed at controlling immigration after a period of unrestricted mobility between Switzerland and EU countries ("mass immigration initiative"). Although this decision was indeed close, the majority support for this initiative challenged two theoretical approaches that have frequently been used to explain the desire to restrict immigration. Firstly, this desire is often related to economic threat, which has been shown to increase if migration occurs under less prosperous economic conditions (Semyonov et al. 2006). However, this threat does not seem to be so prevalent in a rich country like Switzerland, which has almost full employment. Secondly, a further prominent explanation is cultural threat - the idea that natives want to defend what they consider to be their national culture against influences from other cultures. However, a large number of the migrants involved in the current inflow to Switzerland come from Western European countries and should not be perceived by natives as particularly different in terms of their cultural, religious or linguistic background. In addition, Switzerland was for a long time seen as a rather tolerant society, although evidence of some intolerance has recently been growing (Freitag et al. 2015).

Given this particular situation in Switzerland, we will ask how meaningful the two approaches of economic and cultural threat are in regard to exploring preferences in relation to immigration control. We will analyse data from an online survey that was conducted in spring 2014, soon after the decision on the referendum. Consequently, we are not studying long-term attitudes, but rather policy preferences that may have been shaped quite strongly by the discourse and mobilisation at the time of the survey. Moreover, we are focusing on group-specific immigration controls for labour migration coming from European countries only - and not on the potential "deservingness" of individual migrants, which is more often determined by family relations, refugee or asylum seeker status, etc. (see Iyengar et al. 2013; for recent research on Germany: Czymara and Schmidt-Catran 2016). About 1100 respondents with Swiss citizenship from an online access panel were asked for their subjective evaluations with regard to the desire to limit immigration. We applied a factorial survey design that described groups of migrants by referring to their explicit characteristics in terms of origin, skill level, ${ }^{2}$ labour market competition, language skills, and other dimensions related to economic and cultural threat. In a

1 We thank Intervista for the opportunity to use their access panel and for their professional support. The authors are also grateful to Didier Ruedin, Thomas Wöhler and to three anonymous reviewers for very helpful comments on earlier versions of this article. Konstantin Mozer helped us by providing graphical illustrations.

2 Note that we will use the terms "highly skilled migrants" and "highly educated migrants" interchangeably and contrast these groups with "less-skilled migrants" and "less educated migrants." The former group refers to individuals with a tertiary-level education or an equivalent. 
factorial survey design, all these characteristics ("dimensions") were experimentally varied, i. e. they were independent from each other. By implementing the survey experiment, the causal effect of the characteristics on the desire for migration control - often correlated in reality (such as skill level and country of origin) - can be identified more easily. This research strategy significantly transcends the usual postvote survey conducted by the VOX consortium (Sciarini et al. 2014), which mainly focuses on the correlations between voters' characteristics and voting behaviour in Swiss referenda. We are not interested in (re-)interpreting the voting behaviour, but rather in differentiating between distinct characteristics of migrant groups and analysing their influence on the (stated) desire for immigration control. Therefore, our research strategy reflects some recent critiques about the questionable status of causality in most research on "anti-foreigner sentiment" (e.g. see the review by Zamora-Kapoor et al. 2013). We build upon several existing studies using splitballot experiments, such as Hainmueller and Hiscox's (2010) study on the role of economic competition between migrants and natives with similar skill levels and Sniderman, Haagendoorn and Prior's (2004) survey experiment about the role of economic versus cultural threat (for a review: Hainmueller and Hopkins 2014). At the same time, our research moves beyond these studies by focusing precisely on the desire for immigration control, and by studying the role of cultural and economic threat simultaneously across specific origin groups.

\section{The role of economic and cultural threat and group size in exploring immigration control and anti-immigration attitudes}

Research on natives' attitudes toward migrants and immigration has long focused on individual-level correlates in single national contexts. Numerous studies based on survey data have demonstrated the crucial role of respondents' characteristics, such as contact with members of minorities (see Wagner et al. 2003; Weins 2011), education (Hello et al. 2002), sense of national identity and national pride, as well as political orientation (Hjerm 1998; Lewin-Epstein and Levanon 2005). More recent studies have tried to overcome the narrow individualistic focus by studying the interaction between natives and migrants as well as contextual characteristics (Ceobanu and Escandell 2010). Many of these studies have drawn on the work of Herbert Blumer (1958) and emphasised the role of group threat, i. e. challenges to perceived group privileges, in explaining natives' dislike of migrants - and variation therein (Quillian 1995). These privileges can be of an economic or a cultural nature.

In terms of economic threat, natives may, depending on their individual characteristics, feel that large-scale immigration increases competition for scarce resources such as jobs or income, particularly in times of economic crisis (see for review: Hatton 2014, 46-47). In order to measure economic threat empirically, it 
is important to capture the specific constellations in which feelings of threat arise among different subgroups of natives. This, in turn, requires data that allow for the identification of a "'most likely case,' one where economic threat is expected to be present" (Malhotra et al. 2013, 392). Using data from the United States (US), the authors argued that "past research may have failed to find evidence of economic factors underlying anti-immigration sentiment not because labor-market threat has no effect on people's preferences, but because for a large share of Americans, immigrants do not pose such a threat" (Malhotra et al. 2013, 405). According to the "labor market competition hypothesis" (Scheve and Slaughter 2001), the most important precondition for the emergence of perceived migration-related economic threat is that subgroups of natives experience large-scale immigration by migrants with similar skill levels. However, economic threat may also arise if natives feel that immigration increases fiscal pressure on social security systems in general (see Helbling and Kriesi 2014). Worries about newcomers' impact on already tight housing markets can contribute to this type of threat as well. The general size of migrant groups is an important factor in the potential perception of economic threat.

Empirical studies of economic threat have provided, with respect to individual characteristics, ample evidence that "less-skilled (more skilled) people prefer morerestrictionist (less restrictionist) immigration policy” (Scheve and Slaughter 2001, 144), while also demonstrating that this relationship is particularly strong in high per capita GDP countries (Mayda 2006). It is important to note, however, that there are numerous reasons why low skill levels come along with more restrictionist attitudes towards immigration. Education is often used as a proxy for skill level, and this variable is known to affect attitudes about immigration via a broad set of mechanisms (Hello et al. 2002), many of which are unrelated to economic competition. In fact, recent reviews suggest that economic threat plays a rather limited role in explaining migration-related attitudes (Hainmueller and Hopkins 2014). One problem with explanations that start out from economic threat is that less educated natives worry more about competition from less educated migrants but highly educated natives seem to not oppose to highly educated migrants (as one might expect on the basis of a model that focuses on individual economic competition; see O'Connell 2011). Helbling and Kriesi (2014), for example, studied how migrants' skill levels affected the attitudes of highly skilled and less-skilled natives, and found that both groups favoured highly skilled migration (see also Czymara and Schmidt-Catran 20163). Explanations for this phenomenon include arguments that skilled natives are better protected against lay-offs, that people have a general understanding of highly skilled migrants being good for the economy, and that inflows are dominated by low-skilled migrants in many receiving countries.

3 Despite this study's focus on hostility toward immigrants, we include it because of its particular relevance in terms of design. 
However, the interplay between respondents' and migrants' characteristics in terms of skill level or education has rarely been studied systematically across different migrant groups and immigration contexts. While Helbling and Kriesi's 2014 study contained explicit information on the ethnic origin of migrants (which was kept constant; the authors only varied the skill levels), most other studies have left this open. Given that many studies were conducted in countries with overwhelmingly low- or medium-skilled immigration levels, most respondents in surveys on migration-related attitudes could be expected to associate migration with less-skilled inflows (for the US see Scheve and Slaughter 2001, 135). The general finding that both highly skilled natives and less-skilled natives preferred highly skilled migrants thus might just reflect the fact that highly skilled natives are seldom confronted with many migrants with skill levels similar to their own.

In fact, the few studies that have focused on a context in which there were many highly skilled migrants, or that have asked explicitly about origin groups with high aggregate skill levels, suggest that perceived or real competition is an issue for highly skilled natives as well (see Malhotra et al. 2013). Facchini and Mayda $(2012,191)$ showed that "the higher the education level attained by the respondent, the lower is the probability that he favours good educational qualifications of immigrants." The study by Helbling $(2011,19)$ revealed that, in Switzerland, a country with many low and highly skilled migrants, the well-known pattern that highly skilled natives were more positive toward migrants than less-skilled natives disappeared when attitudes to Germans - a large and highly skilled group - were analysed. Likewise, Spies and Schmidt-Catran showed that skilled migrants to Switzerland (Germans, French and Italians) evoked equally strong feelings of economic competition among natives as less-skilled ones (2016). In a vignette study on the openness towards migrants in Germany, Czymara and Schmidt-Catran (2016) demonstrated that natives in general preferred highly skilled migrants to less-skilled migrants. However, this preference was less pronounced among highly than among less educated natives. In sum, these results suggest that an explanation emphasising the role of perceived economic competition deserves closer scrutiny, ideally by taking migrants' explicit characteristics (e. g. skill level and other relevant dimensions), as well as the size of the migrant groups, into account more systematically.

As mentioned above, migrants can also be perceived as a threat to national identity and culture, in terms of being seen as a cultural threat. Sniderman et al. $(2004,36)$ have argued that cultural or identity threat can be expected to be a "function of perceptual distinctiveness, salience, and entativity," the latter referring "to the perceived internal cohesiveness of a group" (see also Zárate et al. 2004). Antiimmigration attitudes can thus be expected to be strong when allegedly culturally dissimilar groups immigrate (distinctiveness), when there is a lot of debate about them (salience), and when those groups are perceived as forming segregated "communities" (entativity). Of course, it is even more demanding to capture cultural threat 
"objectively" than it is to capture economic threat. Who is perceived as a threat to group identity may vary across groups and contexts, and this may not depend on belonging to a different denomination. This argument was made by Helbling, who analysed the general "likability" of Germans in Switzerland and referred to Theiler (2004) (going back to Sigmund Freud), claiming that "[s]mall cultural differences (...) are typically fragile and often result, according to Theiler's argument (...) in 'subconscious fears of insufficient separation from and damaging exposure to the other category" (Helbling 2011, 14f.). ${ }^{4}$ In brief, cultural threat can arise from the cultural difference as well as from the cultural similarity of migrants.

Turning to the explanatory power of cultural or identity threat in regard to sceptical attitudes toward immigration, some authors argued that this threat was more important than economic threat (Sniderman et al. 2004; Sides and Citrin 2007; Manevska and Achterberg 2013). On the individual level, preferences for cultural unity, national pride and similar indicators were used to predict the level of perceived cultural threat (Chandler and Tsai 2001; Lewin-Epstein and Levanon 2005; Sides and Citrin 2007).

Often, cultural threat is captured by looking at the share of migrants from non-EU countries (Manevska and Achterberg 2013), a simple indicator in crossnational studies. There are very few studies analysing the interaction between natives' individual and migrants' group characteristics, most importantly a group's cultural background. An exception is again the study by Helbling $(2011,19)$, who showed that respondents who think that Swiss culture is in danger have generally more hostile attitudes toward both German and Serbian migrants, but that this effect is much stronger for the latter group.

Independent of the nature of threat, the size of the migrant population or of immigration inflow is an important and frequently studied determinant of migration attitudes at a contextual level. Both economic and cultural threat are expected to increase with the size of the migrant population. In fact, several studies have supported the view that large and/or increasing numbers of migrants intensify antiforeigner sentiments (Quillian 1995; Semyonov et al. 2006; Meuleman et al. 2009; Schmidt-Catran and Spies 2016). ${ }^{5}$

It is important to note that the majority of studies found support for the relevance of both economic and cultural threat (for Switzerland see Ackermann and Freitag 2015; Spies and Schmidt-Catran 2016), and both are also likely to be correlated with the size of the migrant population (see Manevska and Achterberg 2013,439 ) and their salience in the receiving countries (for a review: Dancygier and Laitin 2014,47 ). In order to tackle the problem of correlated explanatory factors, some studies have not relied solely on survey data, but rather on a combination

$4 \quad$ His data source was a regionally restricted survey in Zurich in 1994/1995.

5 That said, empirical evidence on group size effects is rather mixed overall. Pottie-Sherman and Wilkes (2017) reviewed existing studies and demonstrated that size effects mainly depended on the specific measurements of group size and prejudice. 
of survey and experimental data (Sniderman et al. 2004; Hainmueller and Hiscox 2010; Helbling and Kriesi 2014). What is still needed, however, is a more comprehensive analysis of the role of economic and cultural threat in specific constellations of respondents' and migrant groups' characteristics. This desideratum is supported by recent findings based on a survey study in the UK showing that respondents have usually very diverse and specific understandings when they think of migrants (Blinder 2015).

In our study, we will let respondents evaluate the perceived desire for immigration control in relation to different groups. We will do so by using a considerably higher number of experimentally varied dimensions describing migrant groups than in most previous studies, which allows us to test in much greater detail which specific constellations define "threats" to groups of natives, and how this interrelates with the size of migrant groups.

\section{Current situation in Switzerland and expected results}

Given the general economic wealth and the favourable labour market conditions in Switzerland, the country has a long and continuing tradition of immigration. 167000 foreigners immigrated to Switzerland in 2013, with a majority being Europeans (128000; among these, 103000 from EU-17 countries). Given that the country has about 8.1 million inhabitants, these numbers are comparatively high compared to other European countries (Switzerland was only behind Luxembourg and Malta as the countries with the largest shares of migrants per inhabitant in 2014; source: Eurostat 2014). ${ }^{6}$ After a period of unrestricted migration from EU countries to Switzerland based on bilateral treaties, these migrants from the EU were a focus of the "mass migration initiative," which sets it apart from previous migration-related initiatives, such as the ban on minarets ("Initiative gegen den Bau von Minaretten") or the drive to expel foreigners with a criminal record ("Ausschaffungsinitiative"). A further aspect which is also special to the Swiss context is that many new migrants to Switzerland are highly skilled. In 2013, incoming Germans were by far the largest group, with 26400 individuals moving to the country, followed by migrants from Portugal, Italy and France. ${ }^{7}$ Migration from Eastern (EU) Europe was on a much lower level (e.g. only 453 migrants from Croatia were registered in 2014;

6 http://ec.europa.eu/eurostat/statistics-explained/index.php/File:Immigrants,_2014_\%28p er_1_000_inhabitants\%29_YB16.png.

7 According to the Swiss Federal Statistical Office, about 54\% of Germans living in Switzerland have tertiary education and only $7 \%$ primary secondary education as their highest level of education - they are thus not only the largest immigration group but also a highly skilled one (French: about $58 \%$ and $17 \%$, Italians: about $19 \%$ and $44 \%$, Croatians: $10 \%$ and $41 \%$, and Romanians $50 \%$ and $21 \%$; data for the year of 2013 provided by the Federal Statistical Office on request). 
source: Federal Statistical Office). ${ }^{8}$ Because of the general economic prosperity in Switzerland, however, "poverty migrants" from EU member states might be attracted to the country and put a strain on the social security system. However, most European migrants have found a job in Switzerland and have not claimed social security benefits. Furthermore, continuing migration might also worsen the situation in already tight housing markets - and, related to this, might evoke worries about overpopulation and negative environmental impacts.

In regard to the economic threat in the Swiss context, it is of further relevance that, while most studies reveal that highly skilled migrants evoke less fear of migrationrelated competition among both skilled and unskilled natives, large numbers of highly skilled migrants may raise fears among skilled natives that their salaries might drop or that their upward mobility will be blocked (Helbling 2011, 19). Regarding cultural threat, the general finding that migrants who are perceived to be culturally similar generally evoke less of a sense of cultural threat than those perceived to be culturally distinct (Spies and Schmidt-Catran 2016, 38) might be challenged by the reverse argument that cultural threat can also stem from groups too similar, because they might be perceived as diluting one's own culture. For instance, there were complaints by the supporters of the initiative that children in Kindergarten speak the "standard German language" rather than Swiss German."

What are our main expectations for the Swiss context? We expect that the natives' desire for immigration control will be influenced by perceptions of economic threat: Migrants who are perceived as direct competitors for jobs are not as welcome as migrants who do not compete with natives. Regarding the skill level, we expect, in general, more opposition to low-skilled migrants than to highly skilled migrants. Given our theoretical arguments outlined above and previous empirical findings on this issue, we expect the preference for highly skilled migrants to be less pronounced among highly skilled natives. This should be particularly pronounced when highly skilled natives evaluate large immigrant groups.

As both types of threat are not exclusive, we further expect that the desire for immigration control will be triggered by cultural threat as well. Culturally more distinct migrant groups and migrants who seem to refuse to adapt to Swiss culture should cause a higher desire for immigration control. Again, cultural threat should be more pronounced for larger groups of migrants. As mentioned above, cultural threat may also be triggered by migrant groups that are culturally rather similar, if the migrant groups in question are large and potentially highlight a small but distinct cultural gap. Finally, in order to analyse respondents' heterogeneity regarding cultural orientations, we assume that natives who express a higher level of Swiss national pride will be affected by cultural threat more strongly.

8 Excel tables available from: http://www.bfs.admin.ch/bfs/portal/de/index/themen/01/07/blank/ key/02/01.html.

9 http://www.masseneinwanderung.ch/downloads/argumentarium_vi_masseneinwanderung_low. pdf. 


\section{$4 \quad$ Data and methods}

Starting out from the theoretical arguments and the expected results outlined above, our measurements need to take into account that the perceived threat evolves in quite specific constellations of natives' predispositions and migrants' characteristics, and may vary across groups that differ with respect to size and cultural background. In order to tackle this challenge, we employed a factorial survey experiment that asked respondents to evaluate short descriptions ("vignettes") that were composed of several different characteristics ("dimensions"). The detailed descriptions of - in our case - types of migrants allowed more subtle and less abstract questions than standard item instruments on immigration attitudes and at the same time a more fine-grained and focused analysis of specific constellations than in split-ballot experiments or previous factorial surveys (Hainmueller and Hiscox 2010; Helbling and Kriesi 2014). Within the factorial surveys, the experimental variation and high standardisation of stimuli enable us to clearly separate perceptions of economic and cultural threat and possible variation across origin groups. Furthermore, the simultaneous variation of many dimensions can reduce socially desirable response behaviour (Auspurg and Hinz 2015). Most importantly, however, the factorial survey design with vignettes describing different migrant groups has the great advantage that we control explicitly and simultaneously for all characteristics mentioned in the vignettes. In other words, we make the migrants' characteristics absolutely clear. This seems to be a major step forward compared to most previous research, because we can now disentangle separate characteristics that are often assumed to go together more or less "automatically". For instance, with simple item questions, migrants from Germany (from a non-Western context) coming to Switzerland are likely to be associated with having a high (low) skill level, while in our factorial survey experiment both factors (country of origin and skill level) can be clearly disentangled.

We implemented our survey experiment in 2014 via an incentivised online access panel run by a Swiss market research firm (http://www.intervista.ch/de) soon after the referendum took place (on 9 February; our fieldwork lasted from $26 \mathrm{March}$ to $4 \mathrm{May})$. This short time distance from the voting day of the initiative makes it likely that our measurement reflected the political debate about the initiative and the SVP's mobilisation campaigns. We assume that the closeness to these debates raised the respondents' awareness of the topic. The vignettes of our study referred to this initiative and asked for a more fine-grained evaluation of immigration control than respondents could express by voting for or against the initiative. The online access panel contained over 50000 participants, living in both the French- and German-speaking regions of Switzerland. Unfortunately, the panel did not cover the Italian-speaking canton Ticino, where the initiative was approved by a comparatively high margin. Note that our research focuses more on effects of specific constellations of migrant groups and their influence on the desire for im- 
migration control than on explaining the varying level of support for the initiative by respondents' characteristics or by region. Panelists were invited to participate in our survey until a sufficient number of respondents was reached; the market research firm sent out one reminder. After successfully recruiting 1432 individuals, among them 1139 with Swiss citizenship, the survey was closed. Checks of the marginal distributions of sociodemographic variables revealed the typical overrepresentation of highly educated respondents in population surveys and web surveys in particular. Note that factorial surveys, like all experimental designs, do not require a random respondent sample for causal conclusions about the effects of experimental stimuli (i. e. the vignette variables). What is crucial for the internal validity is a randomised allocation of stimuli (vignettes) to participants, which we successfully implemented (see below). However, a heterogeneous population survey, such as the online access panel, nevertheless provides results with much greater generalisability (external validity) than the application of such survey experiments in homogeneous (e.g. student) samples only.

The questionnaire, available in German and in French, asked respondents about whether they participated in voting and which way they voted, and about their basic individual characteristics, particularly those that have proven to be important predictors of immigration-sceptical attitudes, such as education level and national pride. The vignette module contained four vignettes, i. e. descriptions of groups of migrants that varied with respect to the following six dimensions:

1. Education (regular school degree only versus university degree, two levels). This dimension indicates migrants' skill levels. This dimension is included in order to study the general effect of skill level on immigration control, and to match it with the skill level of respondents and, therewith, to test our expectations regarding economic threat. ${ }^{10}$

2. Labour market competition. Intention to look for a job vacancy that could be filled by a native Swiss versus intention to look for a job for which a Swiss applicant is not available (two levels). Migrants looking for a position that could be filled by a native can be expected to evoke stronger feelings of economic threat than those who plan to take on jobs that cannot be filled by natives.

3. Language skills (speaking German and/or French, four levels). ${ }^{11}$ Cultural threat can be expected to be stronger among migrants not speaking one of the Swiss languages. Of course, information on German/French language skills was skipped for migrants coming from Germany/France.

10 From a theoretical point of view, it would have been desirable to capture migrants' characteristics, such as their skill level, in a more detailed way, e. g. by including information on migrants' occupations. However, this would have required very large numbers of vignettes and was not possible given the scale of our study.

11 The four levels are "speaks French and German," "speaks French (but not German)," "speaks German (but not French)," and "speaks neither French nor German." For the analyses, we separated two factors with dummy coding French (yes/no) and German (yes/no). 
4. Cultural distance. Willing to adapt culturally vs. unwilling to adapt to the Swiss lifestyle (two levels). We use this dimension as an indicator of cultural threat, which can be expected to be high if migrants do not want to adapt to the Swiss style of living. This dimension explicitly refers to assimilation that determines the 'citizenship regime' (naturalisation) in Switzerland (Guimond et al 2014, 152). ${ }^{12}$ In about one-third of the vignettes, we deleted information about this dimension. Analysing the impact of "no information" on the demand for immigration control will reveal natives' "default" (or stereotypical) assumptions regarding migrants' cultural adaptation. Note that the information condition was only varied between respondents, i. e. all vignettes per respondent either contained information on the two levels of willingness or "no information." We avoided single respondents receiving a different amount of information on cultural distance.

5. Nationality of origin (six levels). This dimension provides important clues about group-level characteristics. Note that we included exclusively EU and European Free Trade Association (EFTA) migrants, since both were the focus of the initiative. ${ }^{13}$ The dimension of nationality serves as an indicator for the size of the origin group. We have argued above that the extent of threat migrants' characteristics evoke depends on the size of a group. Furthermore, we distinguish between Western and non-Western groups to vary migrants' general cultural distance. We took all this into account by asking about groups that dominate current inflows, with Germans, French and Italians (Western) being among the largest groups in recent years (www.bfs.admin.ch). These are compared with smaller groups, such as Norwegians (Western), Romanians and Croatians (non-Western).

6. Intention to stay permanently versus temporarily, i.e. one or several years (three levels). It is unclear whether temporary migrants evoke more or less threat. On the one hand, they can be expected to maintain their own style of living more strongly than permanent migrants. On the other hand, they may be perceived as economically less threatening because they often re-migrate if the economy gets worse and jobs become scarce. It remains an empirical question as to how the intended length might impact upon feelings of threat.

Note again that this design includes a higher number of experimentally varied dimensions than most prior studies that used an experimental survey design (e. g. see Helbling and Kriesi 2014 with four dimensions). As we pointed out above, the main advantage of our design is having a higher amount of information in the vignettes.

12 Naturalisation rates are comparatively low in Switzerland. According to Guimond et al. (2014), decisions on naturalisation in Switzerland are mainly made upon the degree of assimilation while cultural differences are much more tolerated in other countries.

13 In 2014, Germany, France, Italy, Romania, and Croatia were EU member states (for which bilateral treaties between EU and Switzerland were effective), while Norway, like Switzerland, belonged to EFTA. 
It is therefore less likely that evaluations are based on characteristics of the different (ethnic) groups that are not explicitly specified in the vignettes. At the same time, it allows us to test interactions between the different dimensions (such as interactions between nationality of origin and skill level). We used all possible combinations of dimension levels: the "full factorial" for the described six dimensions consisted of $2 \times 2 \times 4 \times 3 \times 6 \times 2=576$ different vignettes. We blocked all these 576 vignettes to 144 decks, each containing four different vignettes in random order. By design, the full factorial is uncorrelated and balanced with the one peculiarity already mentioned: We left out information on migrants' willingness to adapt culturally for about one-third of our respondents and varied this dimension only between respondents. Using the full factorial allows us to estimate all interaction terms of interest. The correlation matrix and the distribution of vignette variables in the realised sample (vignettes with valid evaluations) are given in Table A2 (Appendix). One clearly sees that the realised sample was balanced (all levels appeared with approximately equal frequency) and orthogonal (all correlations coefficients were close to zero).

For each type of migrant (see Figure 1 for a sample vignette) the respondent had to rate whether he or she thought that immigration to Switzerland should be allowed unlimitedly, should not be allowed at all, or something in between (sevenpoint scale, with higher values indicating stronger support for immigration control; mean value: $3.69, \mathrm{SD}: 2.01$ ). This was further differentiated to refer to immigration to Switzerland in general and to immigration to the canton where the respondent lives. ${ }^{14}$ Both experimental splits (vignettes with and without information on migrants' willingness to adapt culturally) and all different questionnaire versions were randomly allocated to the respondents who participated in the survey experiment. ${ }^{15}$

For the purpose of our analysis, we distinguish between respondents with or without tertiary/university education, and respondents with or without a high level of national pride. ${ }^{16}$

All statistical analyses are based on ordinary least squares (OLS) regressions with the robust standard errors clustered on the respondent level. ${ }^{17}$ The dependent variable is the desired level of immigration control. Models are estimated with vignette vari-

14 We report the estimations for the national level only. Results for the cantonal level do not differ substantially.

15 The ordering of the four vignettes scenarios was randomised for each respondent. Random assignment was confirmed by thorough checks.

16 National pride was measured by a standard item question: "How proud are you of being Swiss?" (high pride: "very proud" $=47.1 \%$ ). Respondents with high educational level were measured by a tertiary/university degree (34.2\%). Regarding the region, we can distinguish between the western parts of Switzerland (as French speaking) and all other areas (as German speaking). This almost completely correlates with language choice in the online survey.

17 Such models adapt the estimation of standard errors to heteroscedasticity and the clustered (nested) data structure. For robustness checks, we estimated a random intercept model for all vignette variables which provided identical substantive results (available on request). With only four vignettes per respondent, we do not expect large differences between an OLS model and a multi-level regression (Auspurg and Hinz 2015). 
Figure 1 Example of a vignette (varied information highlighted in bold)

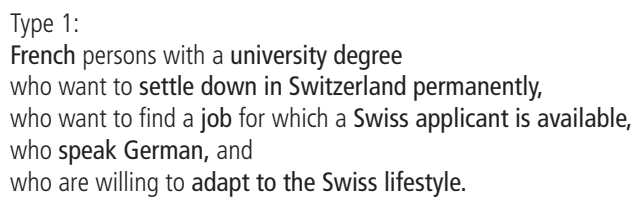

ables as independent variables. For the sake of clarity and brevity, we present plots of the coefficients from OLS models with 95\% confidence intervals (CIs). These reveal how certain characteristics of migrants, as indicated by the dimensions of the vignettes, affect respondents' evaluation of greater support for immigration control (positive values) or greater support for unlimited immigration (negative values). If the $95 \%$ CIs cut the zero line, the coefficients do not differ significantly from the null hypothesis of no impact. Because all vignettes variables are categorical (each with a reference group), the coefficients can be regarded as "effect sizes" that are (by and large) comparable across variables. When we analyse group differences between respondent groups, we additionally estimate cross-level interaction coefficients and report significance tests for these interaction terms. This is done either by a t-test (in case of a single interaction effect) or by a Chow test (F-values, in case of several interaction effects tested jointly; Chow 1960). Respondents with Swiss nationality answered 4489 vignettes in total. There is no indication of survey drop-outs during the vignette module. Missing vignette evaluations are marginal (23 out of 4512).

\section{$5 \quad$ Findings}

What are the determinants of a higher desire for immigration control? Let us first focus on the vignette variables and their influence on the expressed desire for immigration control. Results in Figure 2a (from the regression Model 1 depicted in Table A1 in the Appendix) show that support for stricter immigration control is higher in relation to non-Western groups (Romanians and Croatians) than for 
Western Europeans (significantly positive coefficients with Germans as the reference group). This fits the cultural threat hypothesis based on perceived cultural distance.

Figure $2 a$

Impact of vignette dimensions on stating "should be restricted," regression coefficients and $95 \%$ confidence intervals

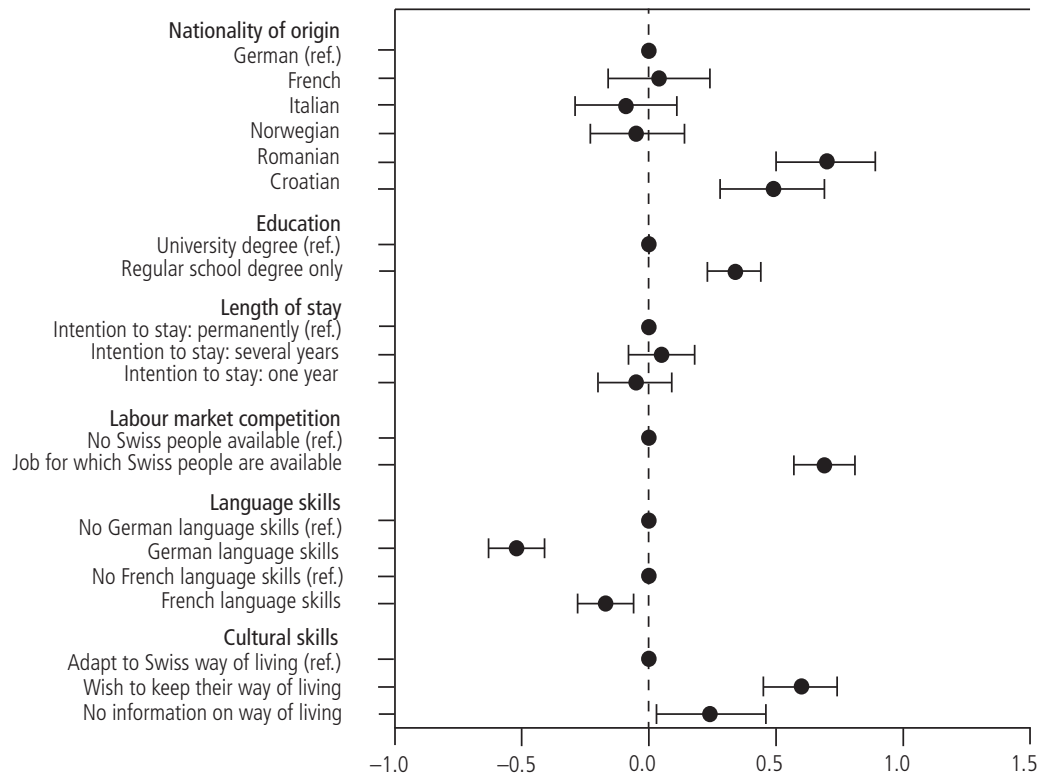

Estimation of one OLS regression model with cluster robust standard errors (see Model 1 in Table A1), number of vignette evaluations $N=4489, R^{2}=0.092$.

Within the group of Western Europeans, no differences can be found, i. e. the Swiss do not opt for stricter control of immigration from Germany (reference group) as compared to immigration from Norway, Italy or France. Thus, comparing Norway (small number of migrants) to the three larger sending countries reveals no direct influence of group size. As found in other studies, less-skilled migrants are less popular than highly skilled migrants. The same applies to migrants who look for a job for which native Swiss applicants are available as well, as compared to those who search for a job for which no native Swiss are available. This is in line with the perceived economic threat hypothesis. Respondents prefer stricter control of migrants who want to maintain their own lifestyle than of migrants who want to adapt to Swiss culture. Interestingly, the judgement of those respondents who have not been given any information about this dimension is similar (they also show a statistically significant preference for higher immigration control, although 
to a somewhat lower extent than those who were told that migrants do not want to adapt culturally). ${ }^{18}$ This result suggests that respondents tend to assume that migrants do not want to adapt culturally by default. Respondents ask for less control when evaluating migrants who speak either German or French. Migrants' planned duration of stay does not play a role. Additional analyses reveal that the labour market variable has the strongest influence (partial correlation of 0.17 ), followed by German language skills and the willingness to adapt to the Swiss lifestyle (partial correlation of 0.13 for both). Moreover, further analyses show that results differ between the Swiss language regions for language skills only: no other effects vary between German- and French-speaking regions. So far, both perceptions of economic and cultural threat play a role. Only one variable measured by group of origin - cultural distance (Western/non-Western) - was found to be relevant, while differences by group size could not be detected.

Now we turn to a more fine-grained analysis by the six countries of origin. Figure $2 \mathrm{~b}$ is based on a subgroup comparison of vignettes by origin groups, and suggests that the general patterns just described do not differ largely across these six origin groups. ${ }^{19}$ However, it is noteworthy that the educational level of migrants does not affect the attitude toward the immigration of French, German and Italian citizens significantly - large migrant groups from neighbour countries - but does so for Croatians and Romanians, and also for the small group of Norwegians. ${ }^{20}$ The pattern suggests that high levels of skills are no longer of advantage when migrants come from large migrant groups. Language skills in German and French are more strongly valued for non-Western origin groups compared to Italians and Norwegians. ${ }^{21}$

In the next step, we will look at exactly those constellations of respondents' and migrants' characteristics that can be expected to increase perceived economic and cultural threat.

Figure 3 a depicts the effects for education and labour market competition by respondents' education. It confirms the findings of Hainmueller and Hiscox (2010) that, irrespective of natives' educational level, less educated migrants are less popular than highly educated ones (interaction term of skill-level and respondents' education n. s. with $p=0.620$ ). This result differs from what one could expect on the basis of a very basic economic threat model, which would predict that natives favour migrants with a different skill level to their own. With respect to another vignette dimension that captures economic threat, namely whether or not a migrant wants to do a job

18 See regression coefficients in Table A1: the estimate is 0.597 for those migrants who want to keep their way of living and 0.244 for those vignettes with no information on the way of living.

19 We simply analysed vignettes groupwise by country of origin, which is legitimised by the experimental setup. All vignettes were randomly allocated among respondents.

20 The interaction terms of the variables for origin group and education are significant at a $5 \%$ level (joint Chow test with F-value 2.65 [df 5], $p=0.022$ ).

21 Again, the interaction terms of the variables for origin group and German and French language skills are statistically significant (joint Chow test with F-values 3.35 [df 5], $p=0.005$ and 2.16 [df 5], $p=0.057$ ). 
Figure $2 b$

Impact of vignette dimensions on stating "should be restricted" by immigrant group, regression coefficients and $95 \%$ confidence intervals

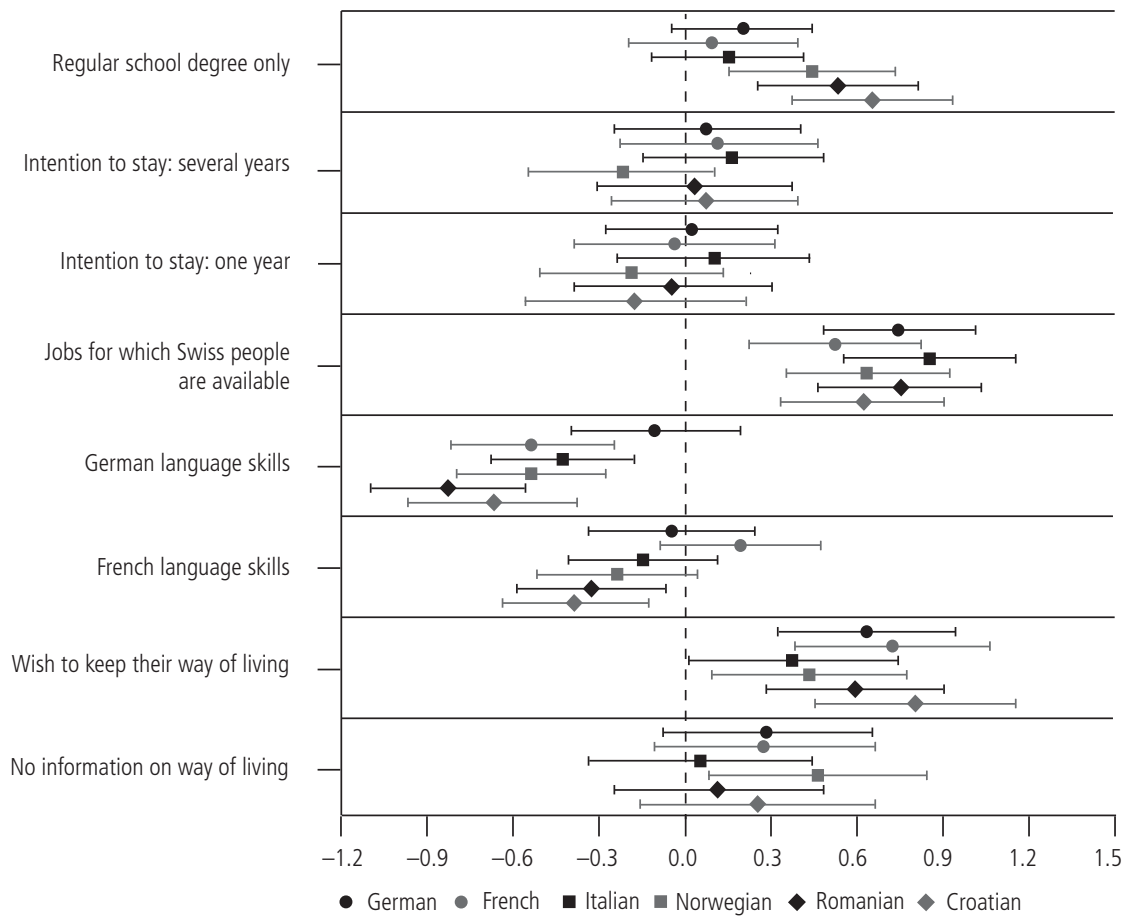

Reference groups: University degree, intended stay: permanently, job that cannot be filled by Swiss people, no German/French language skills, adapt to Swiss way of living.

Estimation of six OLS regression models with cluster robust standard errors, German migrants: $N=763, R^{2}=0.059$, French migrants: $N=729, R^{2}=0.060$, Italian migrants: $N=768, R^{2}=0.069$, Norwegian migrants: $N=733, R^{2}=0.0722$, Romanian migrants: $N=755, R^{2}=0.120$, Croatian migrants: $N=741, R^{2}=0.117$.

for which Swiss workers are available, the pattern is similar: independent of their own skill level, respondents favour immigration control for migrants who want to do jobs for which Swiss people are available (interaction term n. s. with $p=0.512$ ).

As far as economic threat is concerned, highly skilled natives may be in favour of some highly skilled migrants - knowing they are good for the economy. However, highly skilled natives prefer highly skilled migrants only as long as the overall skill level of the group under consideration is low or the highly skilled migrant group is small, so that the newcomers do not increase economic competition among the highly skilled. In Figure $3 \mathrm{~b}$ we thus look into this relation by origin group in order to assess whether highly skilled migrants may increase the desire for immigration 
Figure $3 a$

Economic threat: Impact of vignette dimension "migrants' education" and "availability of Swiss workers" on stating "should be restricted" by respondents' skill level, regression coefficients and 95\% confidence intervals

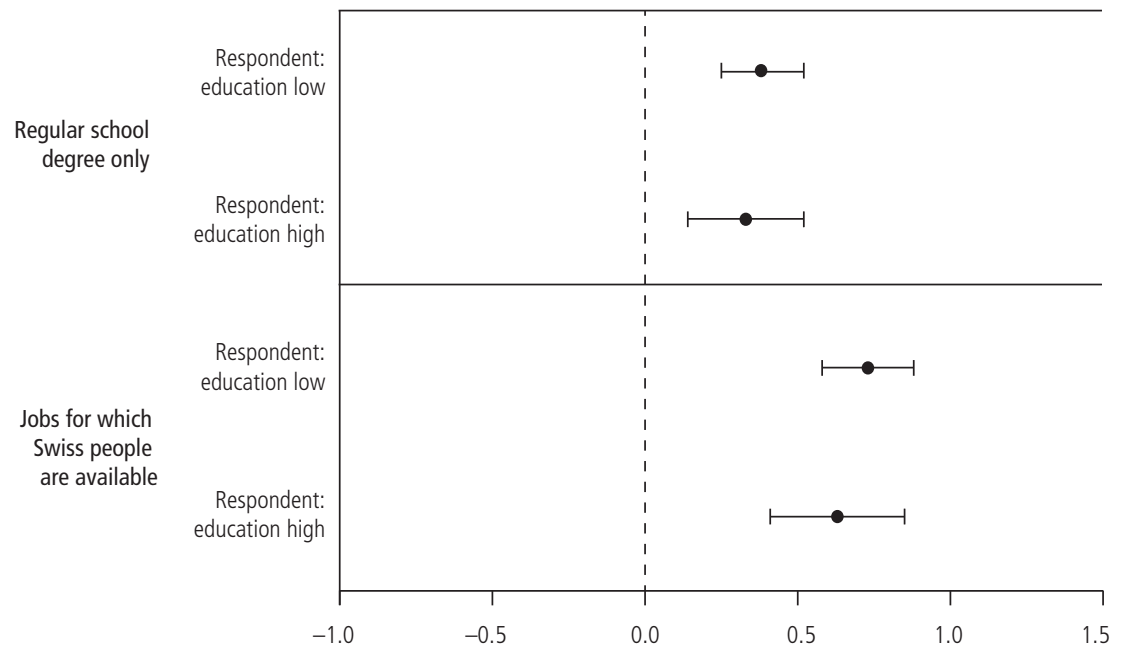

Reference groups: University degree, job that cannot be filled by Swiss. All further vignette variables controlled.

Estimation of two OLS regression models with cluster robust standard errors, respondents with low education: $N=2827$, $R^{2}=0.107$, respondents with high education: $N=1466, R^{2}=0.086$.

control among skilled natives when migrant groups are large. What we see is that once German migrants - by far the largest group of actual inflows (with a very high share of highly skilled individuals) - are considered separately, only less-skilled natives prefer migrants with a university degree to migrants with a regular school degree. Among highly skilled Swiss natives, the preference for immigration control does not differ between migrants with a low or high skill level (the CI for this group intersects with the zero line), a quite astounding finding given the general preference for skilled migrants. This can be interpreted as evidence that once skilled migrants belong to a large (and overall highly skilled) group, highly skilled natives no longer prefer highly skilled over less-skilled migrants. However, some caveats are in order here. First of all, the differences in effect sizes between both groups of natives only show a tendency - they are not statistically significant $(p=0.155)$. Secondly, the pattern looks similar for Croatians, even though for this group highly skilled natives tend to prefer skilled migrants $(p=0.099)$. Romanian and Norwegian migrants are more popular when they are highly skilled for both highly skilled and less-skilled natives (interaction effects n. s. with $p=0.873$ and $p=0.644$ ), while for French migrants the skill level does not matter at all $(p=0.938)$. In regard to Italians, highly skilled 
Figure 3b Economic threat: Impact of vignette dimension "migrants' education" on stating "should be restricted" by immigrant group, respondents' skill level, regression coefficients and $95 \%$ confidence intervals

Effect size: regular school degree only

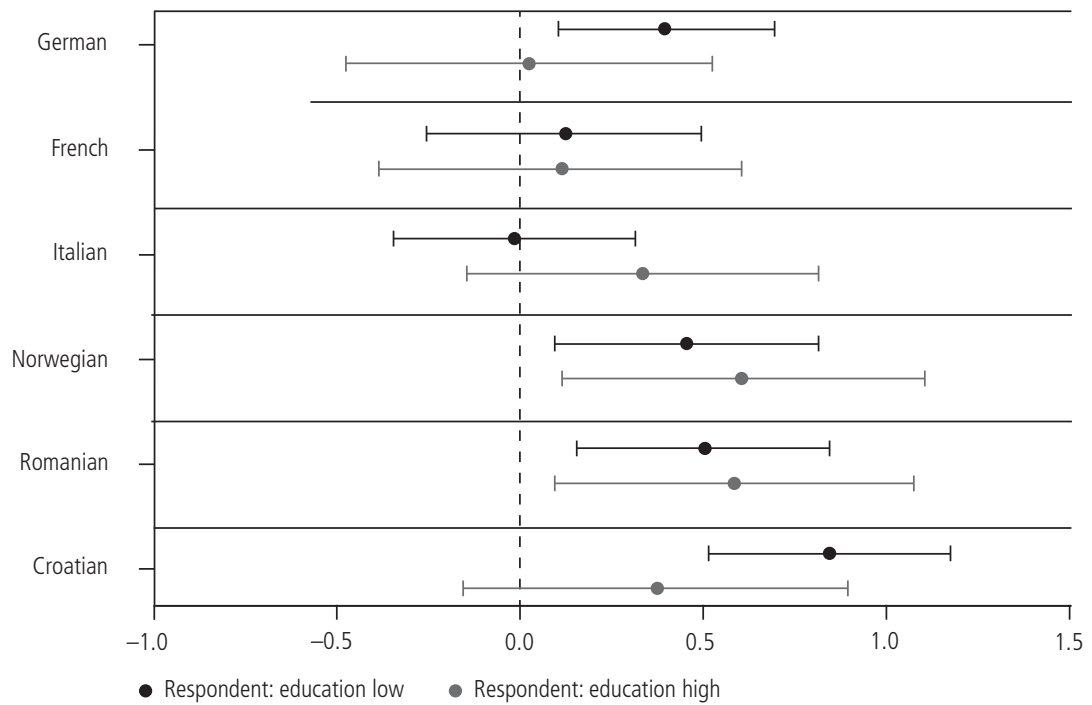

Reference group: University degree. All further vignette variables controlled.

Estimation of 12 OLS regression models with cluster robust standard errors, German migrants/respondents with low education level: $N=499, R^{2}=0.083$, German migrants/respondents with high education level: $N=235, R^{2}=0.047$, French migrants/ respondents with low education level: $N=439, R^{2}=0.102$, French migrants/respondents with high education level: $N=247$, $R^{2}=0.078$, Italian migrants/respondents with low education level: $N=475, R^{2}=0.060$, Italian migrants/respondents with high education level: $N=263, R^{2}=0.107$, Norwegian migrants/respondents with low education level: $N=456, R^{2}=0.085$, Norwegian migrants/respondents with high education level: $N=249, R^{2}=0.082$, Romanian migrants/respondents with low education level: $\mathrm{N}=469, \mathrm{R}^{2}=0.121$, Romanian migrants/respondents with high education level: $\mathrm{N}=252, \mathrm{R}^{2}=0.119$, Croatian migrants/respondents with low education level: $N=489, R^{2}=0.151$, Croatian migrants/respondents with high education level: $N=220, R^{2}=0.119$.

natives tend to ask for more immigration control of low-skilled migrants compared to highly skilled ones, although this effect is not statistically significant $(p=0.164)$.

For ease of interpretation, in Figure 4 we illustrate how the regression effect sizes translate into group differences for distant migrant groups. We show the overall level of desired immigration control expressed by highly skilled and less-skilled Swiss, differentiated by migrants' skill level, and separately for Germans (by far the largest - and most highly skilled - group in our study) and Romanians - a small group, which also tends to be the least popular (see Figure 2). ${ }^{22}$ We can see once more that, in Switzerland, being highly skilled helps migrants to be more popular among

22 We have already reported significant effect sizes before. The graphical illustration (in Figures 4 and 6) merely helps to visualise the findings. 
Figure 4

Economic threat: Support for immigration control of Germans and Romanians by migrants' and natives' education level, mean values by groups and $95 \%$ confidence intervals
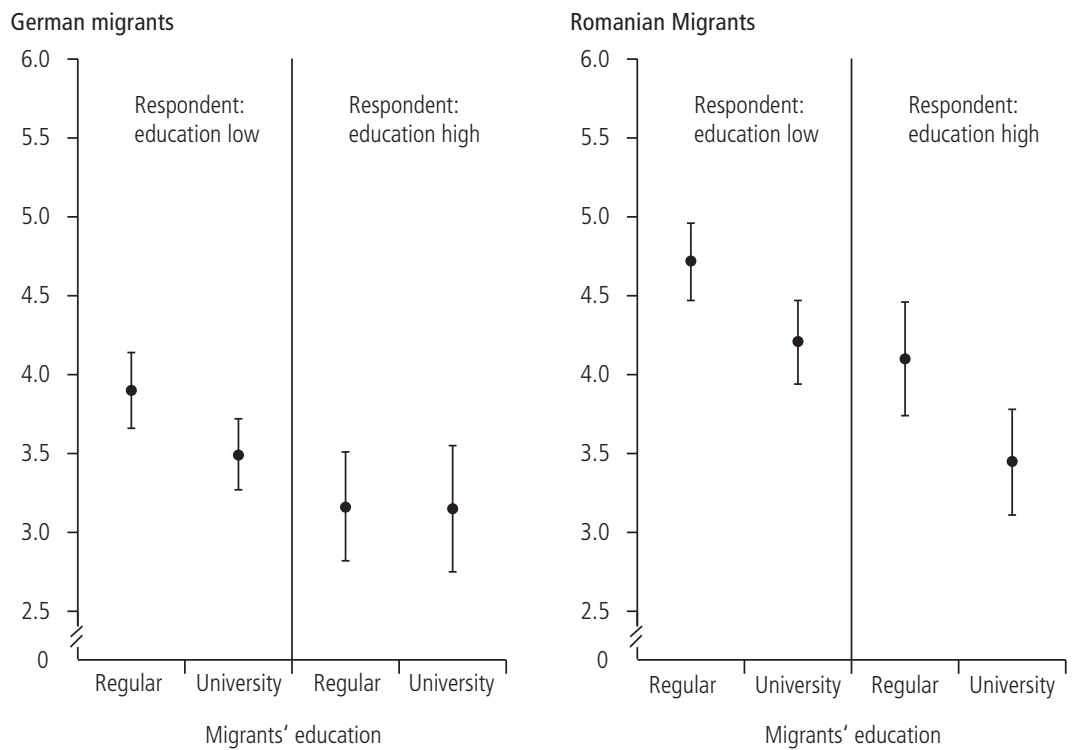

Group-specific means of vignettes' evaluations and $95 \% \mathrm{Cls}$. German migrants with regular school degree/respondents with low education level $N=239$, German migrants with university degree/respondents with low education level: $N=264, G e r-$ man migrants with regular school degree/respondents with high education level: $N=129$, German migrants with university degree/respondents with high education level: $N=109$, Romanian migrants with regular school degree/respondents with low education level: $\mathrm{N}=226$; Romanian migrants with university degree/respondents with low education level: $N=216$, Romanian migrants with regular school degree/respondents with high education level: $\mathrm{N}=116$, Romanian migrants with university degree/ respondents with high education level: $\mathrm{N}=126$.

highly skilled and less-skilled natives unless they belong to a large (and overall highly skilled) group like Germans. In this case, being highly skilled does not increase support among highly skilled natives (the CIs for migrants with regular school- and university degree-level education intersect). One interpretation of this finding is that, when a group is large, perceived competition increases even among highly skilled natives, who usually have little reason to worry about a migration-related increase in economic competition. One has to note, however, that absolute levels of demand for immigration control are lower for German migrants than for those from Romania for both highly educated and less educated Swiss natives (see again Figure 4). However, the greater popularity of Germans as compared to Romanians is rather small ( 0.3 scale points) when it comes to highly educated natives evaluating highly educated migrants. In every other combination of natives' and migrants' 
skill levels, demand for immigration control is about 0.7 to 0.9 scale points lower for Germans than for Romanians.

With respect to cultural threat, we have seen above (see Figure 2) that Western European migrants are more popular than the other groups under consideration here. In addition, Figure 5a reveals that, as was expected for the European migrants under consideration, natives in general (i. e. independent of their level of national pride $)^{23}$ prefer migrants who are willing to adapt to the Swiss lifestyle. A similar pattern can be found when no information on this issue is provided.

Again, the most interesting results become visible by looking separately at the different migrant groups (Figure 5b). As a reminder, we expected that even culturally rather similar migrant groups, such as Western Europeans, would result in a rise in requests for immigration control among natives who are more likely to perceive threats to their own culture - if these migrants belong to very large groups. We can see that, in fact, only Swiss respondents with high levels of national pride ask for immigration restrictions for Germans who want to keep their way of living. For

Figure $5 a$

Cultural threat: Impact of vignette dimension "wishes to keep their way of living" on stating "should be restricted" by immigrant group and respondents' level of national pride, regression coefficients and $95 \%$ confidence intervals

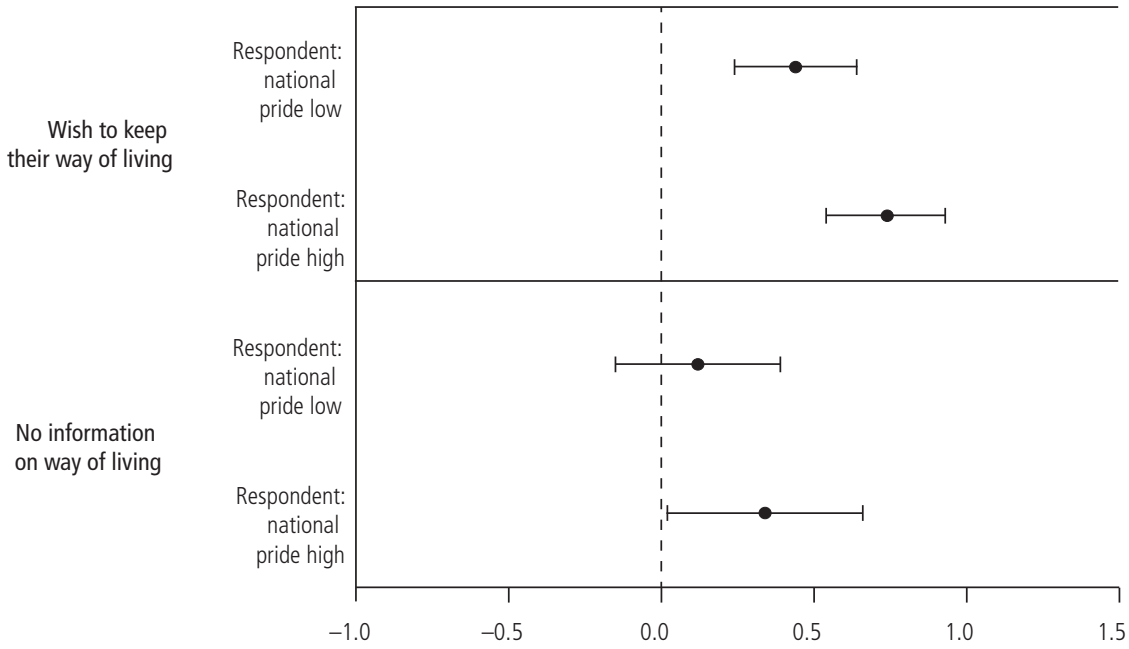

Reference group: Migrants willing to adapt to the Swiss lifestyle. All further vignette variables controlled.

Estimation of two OLS regression models with cluster robust standard errors, respondents' national pride low: $N=2261$, $R^{2}=0.095$, respondents' national pride high: $N=2016, R^{2}=0.107$.

23 The interaction terms of the variables for lifestyle information and respondents' national pride are not significant (joint Chow test with F-value 2.18 [df 2], $p=0.114$ ). 
Figure $5 b$

Cultural threat: Impact of vignette dimension "wishes to keep their way of living" on stating "should be restricted" by immigrant group and respondents' level of national pride, regression coefficients and 95\% confidence intervals

Effect size: wish to keep way of living

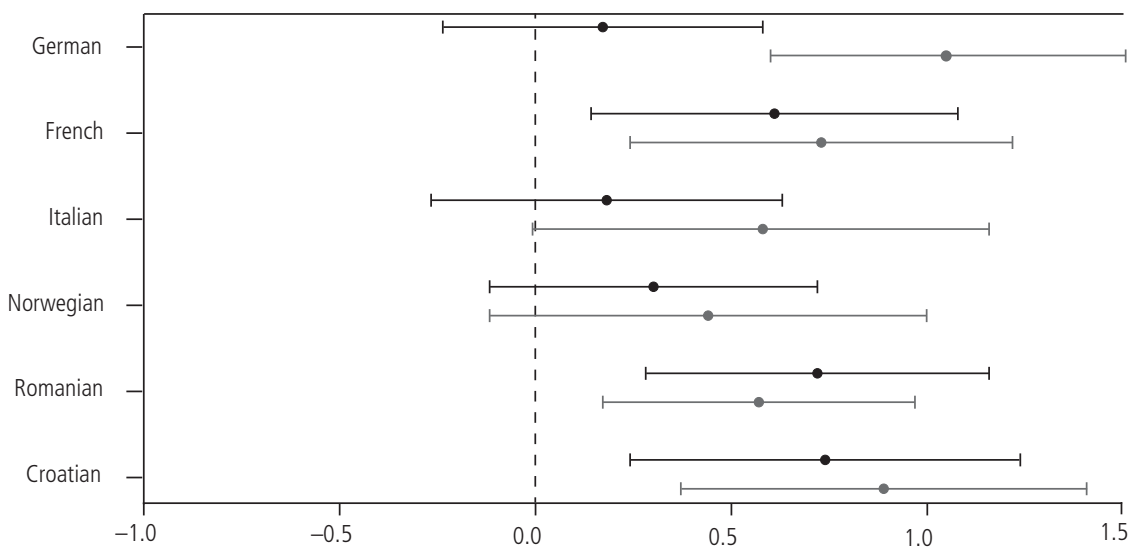

Effect size: no information

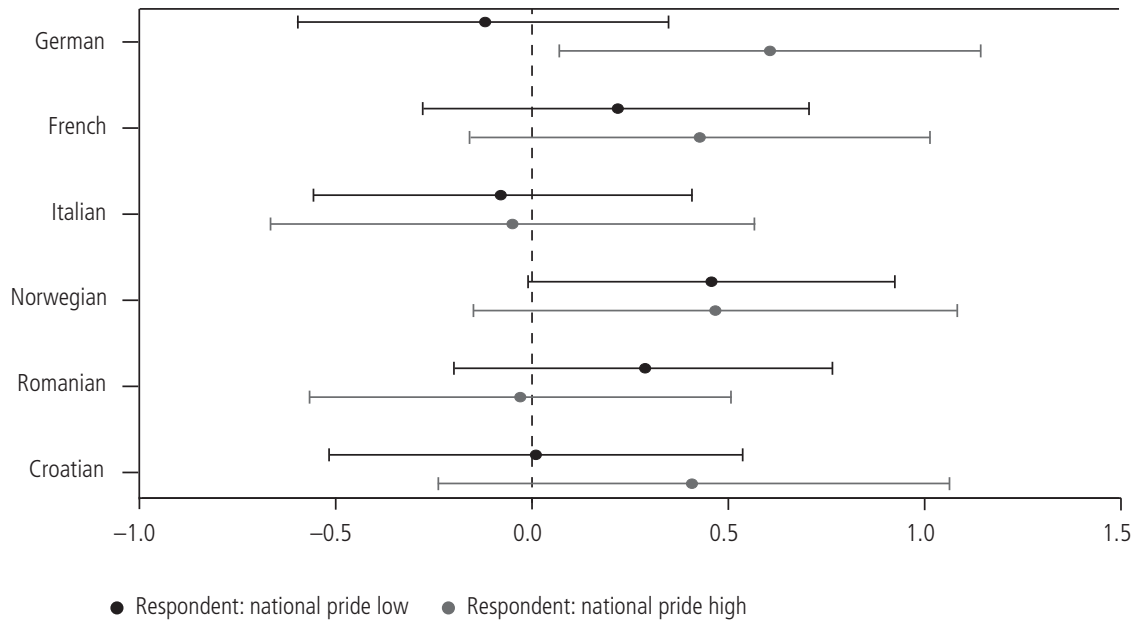

Reference groups: Migrants willing to adapt to the Swiss lifestyle. All further vignette variables controlled.

German migrants/respondents with low national pride: $\mathrm{N}=378, \mathrm{R}^{2}=0.045$, German migrants/respondents with high national pride: $\mathrm{N}=345, \mathrm{R}^{2}=0.112$, French migrants/respondents with low national pride: $\mathrm{N}=350, \mathrm{R}^{2}=0.072$, French migrants/respondents with high national pride: $\mathrm{N}=346, \mathrm{R}^{2}=0.068$, Italian migrants/respondents with low national pride: $\mathrm{N}=400, \mathrm{R}^{2}=0.068$, Italian migrants/respondents with high national pride: $N=339, R^{2}=0.080$, Norwegian migrants/respondents with low national pride: $N=366, R^{2}=0.078$, Norwegian migrants/respondents with high national pride: $\mathrm{N}=331, \mathrm{R}^{2}=0.077$, Romanian migrants/respondents with low national pride: $\mathrm{N}=387$, $\mathrm{R}^{2}=0.112$, Romanian migrants/respondents with high national pride: $\mathrm{N}=330, \mathrm{R}^{2}=0.186$, Croatian migrants/respondents with low national pride: $N=380, R^{2}=0.122$, Croatian migrants/respondents with high national pride: $N=325, R^{2}=0.129$. 
this subgroup of Swiss respondents, Germans who are not willing to adapt culturally are substantively less popular than Germans who plan to adapt culturally. In other words, Germans are the only group for which stricter immigration control was desired by Swiss natives with high levels of national pride only when they are unwilling to adapt culturally. ${ }^{24}$ For Germans, this pattern looks similar when no information on their willingness to adapt is given. This suggests that many Swiss with high levels of national pride assume that immigrant Germans will keep their way of living. Note that this is not the case for the other groups under consideration here. For the other groups, the wish to keep their way of living either leaves the request for

Figure 6

Cultural threat: Support for immigration control of Germans and Romanians by migrants' willingness to adapt to the Swiss lifestyle and respondents' level of national pride, mean values by groups and $95 \%$ confidence intervals
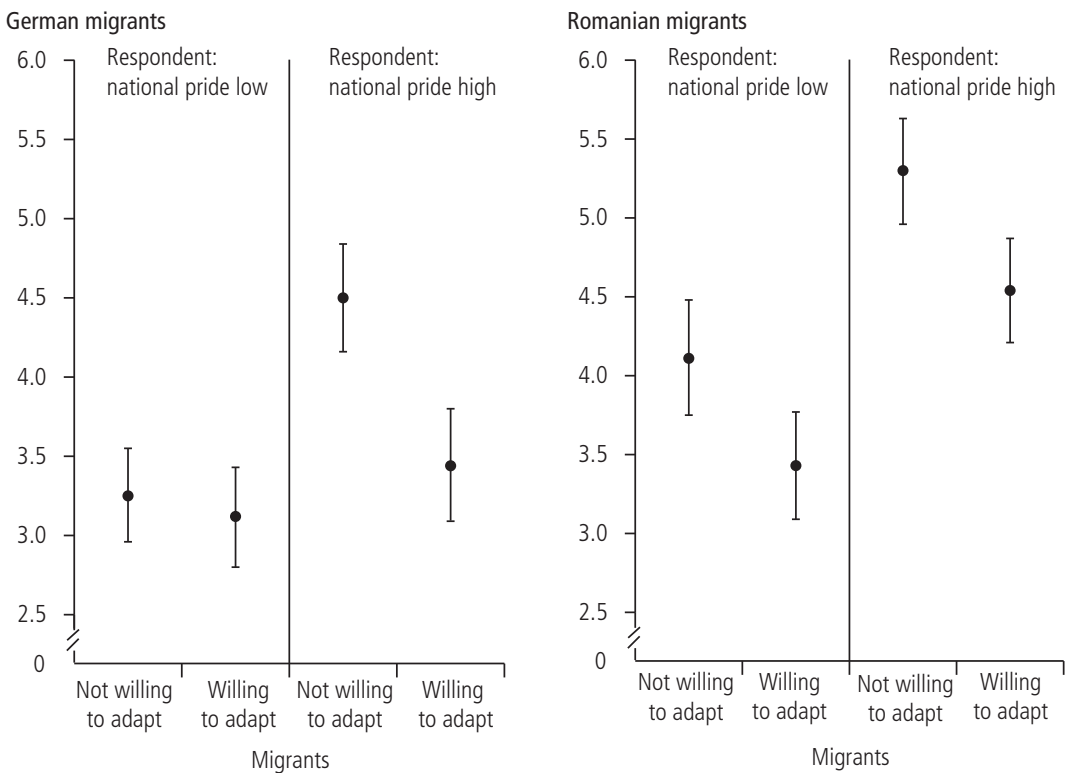

Group-specific means of vignettes' evaluations and 95\% Cls. German migrants not willing to adapt/respondents with low national pride $\mathrm{N}=136$, German migrants willing to adapt/respondents with low national pride: $N=128$, German migrants not willing to adapt/respondents with high national pride: $N=122$, German migrants willing to adapt/respondents with high national pride: $\mathrm{N}=116$, Romanian migrants not willing to adapt/respondents with low national pride: $\mathrm{N}=131$; Romanian migrants willing to adapt/respondents with low national pride: $\mathrm{N}=122$, Romanian migrants not willing to adapt/respondents with high national pride: $\mathrm{N}=114$, Romanian migrants willing to adapt/respondents with high national pride: $\mathrm{N}=118$.

24 The interaction terms between lifestyle information and respondents' national pride are significant only for the German group of origin (joint Chow test with F-value 4.27 [df 2], $p=0.014$ ). For all other groups no statistically significant differences by respondents' national pride are revealed. 
immigration control unaffected (Norwegians and Italians) or increases it (French, Romanians and Croatians), independent of respondents' levels of national pride.

In Figure 6 we show again the mean values for demand for immigration control for Germans and Romanians, as contrasting groups. The graph reveals that, for Swiss with high levels of national pride, the demand to curb the immigration of Germans who are unwilling to adapt culturally is as high as for Romanians who are willing to adapt culturally. Remember that, once Germans are willing to adapt their lifestyle, Swiss respondents with high levels of national pride do not differ from those with low levels of national pride in terms of their demand for control of immigration from Germany.

\section{Discussion}

In this article, we used a factorial survey experiment in order to look into the role of economic and cultural threat in explaining support for immigration control. We conducted this experiment with a heterogeneous respondent sample in Switzerland, where support for immigration control is substantial and the majority of migrants come from Western Europe.

Theoretically, we based our study on approaches that explain the desire for immigration control to be a result of perceived economic and cultural threat. Starting out from the criticism that many studies fail to find support for the role of threat because it is not modelled properly (see Malhotra et al. 2013), we implemented a multidimensional design incorporating important characteristics of migrant groups, such as origin (six European countries), skill level, labour market competition, language skills, willingness to adapt to Swiss culture, and intended duration of stay. While most of the direct effects of the vignettes' variables explicitly describing the migrant groups influenced the desire for immigration control, both the theory and previous studies suggested that it would be useful to focus on the interactions between factors that are relevant for perceived economic and cultural threat.

Because of the experimental set-up, we were able to analyse the role of migrants' characteristics independently from each other and in various theoretically relevant combinations. This is a considerable advantage, because attempts to measure the role of (perceived) economic and cultural threat by using survey questions face the problem that the captured attitudes are often triggered by attitudes toward specific large migrant groups, e.g. less educated migrants from a Muslim background in many European countries. Most existing attempts to study the role of economic and cultural threat independently of each other face the problem that they do not take migrants' origin into account systematically and thus ignore the possibility that, for example, cultural adaptation may be more important for large rather than small migrant groups. 
In our study, we were able to show that both economic and cultural threat play a role in exploring support for immigration control, but that feelings of threat seem to become particularly salient in specific constellations of natives' and migrants' characteristics, and only in specific (origin) group settings. With respect to economic threat, our empirical results indicated that both low-skilled and highly skilled natives have a preference for highly skilled migrants, and that highly skilled Swiss natives show considerably lower levels of support for immigration control than the rest of the population. However, a group-by-group comparison revealed that the overall greater support for limited immigration of less-skilled as compared to highly skilled migrants tends to vanish once highly skilled Swiss respondents have to evaluate immigration by Germans, by far the largest - and, on average, highly skilled - migrant group in Switzerland. Even though our results were not totally conclusive across groups, they suggest that it is worth looking into the idea that even highly skilled migrants might evoke feelings of economic threat among natives with similar skill levels when they immigrate in large numbers.

With respect to cultural threat, our results point in a similar direction. Again, only in specific constellations do - overall rather popular - migrants like Germans raise requests for immigration control, namely when Swiss respondents with high levels of national pride evaluate German migrants who do not want to adapt culturally. Swiss respondents with high levels of national pride are only willing to accept further unlimited immigration of Germans if these newcomers are willing to accept the Swiss lifestyle. At the same time, we were able to demonstrate that Swiss respondents assume that such newcomers are not willing to accept the Swiss lifestyle. For other migrant groups there is no clear pattern: Migrants' willingness to adapt culturally decreases support for immigration control for some groups, but leaves it unaffected for others, independent of natives' levels of national pride. For the subgroup of natives with high levels of national pride, being Swiss is a salient part of their social identity. Our results suggest that this identity may be perceived as threatened not only by migrants from an apparently different cultural background but also by the presence of large numbers of foreigners who are not willing to adapt to the Swiss lifestyle, while not being dissimilar enough to stay truly apart from Swiss culture. Seemingly small cultural differences can evoke the desire to demarcate and protect the in-group against a (large) out-group (confirming the results of Helbling 2011). ${ }^{25}$

Our results suggest that the desire for immigration control in some subgroups was stronger than one would expect on the basis of previous studies, and that this may have contributed to the initiative being successful, even though it targeted migrants

25 One further indicator pointing in this direction might be the general discussion on German migrants speaking standard German (as it is spoken in their country of origin) and, thereby, the fear of diluting Swiss culture. Swiss people usually understand and often speak standard German, whereas Germans often have difficulties understanding Swiss German - not to mention speaking it. A more widespread use of standard German could evoke fears that it would come to replace Swiss German in environments dominated by many migrants. 
who are generally popular: namely, Europeans. We should keep in mind that support for the initiative was limited overall, with "only" about a quarter of the total population explicitly voting in favour and the rest not participating in the referendum or rejecting it. Under such circumstances, preferences for limiting immigration that arise in specific constellations of migrants' and natives' characteristics do make a difference. In the Swiss case, our findings shed light on the above-mentioned puzzle that in times of economic prosperity immigration of culturally rather similar and overall skilled migrants can evoke feelings of economic and cultural threat among some subgroups of natives, especially when they arrive in large numbers.

Notwithstanding its merits, our analysis has its limitations. By using an online access panel, highly educated respondents were oversampled, and there might have been some self-selection of respondents given the topic of the survey. Using a more representative survey would be likely to change the descriptive results. We expect, however, that our substantive analyses regarding the causal impact of vignette dimensions and their interplay with respondent variables would not change - unless meaningful moderator variables were omitted (Auspurg and Hinz 2015). In addition, the survey was conducted during the rather heated atmosphere soon after the referendum, and it is thus questionable to what extent the results reflect the resultant debate rather than stable attitudes on the issue.

We have also focused on an important though rather narrow aspect of economic threat, i. e. natives' fear that migrants will take their jobs, and did not take into account other aspects, such as migration-related fiscal pressure or worries about tightening housing markets. An additional restriction is that we purposefully only analysed labour migrants from European countries. Thus, other migrant groups, such as refugees and asylum-seekers, were not covered: The acceptance of such groups in receiving countries is obviously more driven by feelings of deservingness, which we explicitly excluded from our analysis.

We are also aware that the operationalisation of group size is only imperfect in our study because we relied on some common knowledge about group sizes by countries of origin. We believe this assumption is justified - Swiss respondents probably know very well that Germans, Italians, and French form larger groups, whereas Norwegians, Romanians, and Croatians are smaller. Since we asked about specific and "real" groups, we could not vary group size experimentally. Thus, our interpretation of group size effects has some limitations. Finally, one could argue that the size of a migrant group influences its probability of having had contact with natives and, thus, indirectly reduces negative feelings toward it (Allport 1954). This issue needs further research - in particular for groups of labour migrants with different skill levels.

All in all, our results should inspire efforts to carry out similar experiments with further respondent samples and different groups of migrants in different country contexts. This would allow us to refine the study of the specific contexts that are 
relevant in the desire for stricter immigration control. It would reveal whether or not the pattern we have found for German migrants in Switzerland in particular is typical for large and overall highly skilled and culturally "similar" origin groups. After all, many countries are trying to attract increasing numbers of skilled migrants and many experience substantial immigration from their neighbouring countries. Given the increasing heterogeneity of migration inflows, survey data that aim to capture attitudes toward migrants without differentiating between origin groups no longer seem adequate.

Keeping in mind that most German migrants to Switzerland are highly skilled and from a neighbouring country, our results challenge two underlying assumptions in the current debate on immigration. First of all, migration-related cultural threat is not necessarily restricted to allegedly culturally distant migrants, most importantly Muslims. Secondly, one might speculate about the consequences of an international competition for particularly highly skilled migrants. While such competition seems to find broad support by the general public, highly skilled natives' support for unrestricted immigration of highly skilled migrants may not be unlimited once large inflows of highly skilled migrants become a reality. Whether or not this is the reason for the lack of a coherent immigration policy aimed at attracting highly skilled migrants (see Facchini and Mayda 2012) remains an open question.

\section{$7 \quad$ References}

Ackermann, Maya and Markus Freitag. 2015. What Actually Matters? Understanding Attitudes Toward Immigration in Switzerland. Swiss Political Science Review 21(1): 36-47.

Allport, Gordon W. 1954. The Nature of Prejudice. Reading: Addison Wesley.

Auspurg, Katrin and Thomas Hinz. 2015. Factorial Survey Experiments. Quantitative Applications in the Social Sciences 175. Thousand Oaks: Sage.

Blinder, Scott. 2015. Imagined Immigration: The Impact of Different Meanings of "Immigrants" in Public Opinion and Policy Debates in Britain. Political Studies 63(1): 80-100.

Blumer, Herbert. 1958. Race Prejudice as a Sense of Group Position. Pacific Sociological Review 1(1): 3-7.

Ceobanu, Alin M. and Xavier Escandell. 2010. Comparative Analyses of Public Attitudes Toward Immigrants and Immigration Using Multinational Survey Data: A Review of Theories and Research. Annual Review of Sociology 36(1): 309-328.

Chandler, Charles R. and Yung-mei Tsai. 2001. Social Factors Influencing Immigration Attitudes: An Analysis of Data from the General Social Survey. The Social Science Journal 38(2): 177-188.

Chow, Gregory C. 1960. Tests of Equality Between Sets of Coefficients in Two Linear Regressions. Econometrica 28(3): 591-605.

Czymara, Christian S. and Alexander W. Schmidt-Catran. 2016. Wer ist in Deutschland willkommen? Eine Vignettenanalyse zur Akzeptanz von Einwanderern. Kölner Zeitschrift für Soziologie und Sozialpsychologie 68(2): 193-227.

Dancygier, Rafaela M. and David D. Laitin. 2014. Immigration Into Europe: Economic Discrimination, Violence, and Public Policy. Annual Review of Political Science 17(1): 43-64. 
Facchini, Giovanni and Anna Maria Mayda. 2012. Individual Attitudes Towards Skilled Migration: An Empirical Analysis Across Countries. World Economy 35(2): 183-196.

Freitag, Markus, Adrian Vatter, and Sean Mueller. 2015. Switzerland's Immigration Challenge. Viewpoints and Insights in the Aftermath of the Mass Immigration Initiative. Swiss Political Science Review 21(1): 1-4.

Guimond, Serge, Roxane de la Sablonnière, and Armelle Nugier. 2014. Living in a Multicultural World: Intergroup Ideologies and the Societal Context of Intergroup Relations. European Review of Social Psychology 25(1): 142-188.

Hainmueller, Jens and Michael J. Hiscox. 2010. Attitudes Toward Highly Skilled and Low-Skilled Immigration: Evidence From a Survey Experiment. American Political Science Review 104(1): 61-84.

Hainmueller, Jens and Daniel J. Hopkins. 2014. Public Attitudes Toward Immigration. Annual Review of Political Science 17(1): 225-249.

Hatton, Timothy J. 2014. The Economics of International Migration: A Short History of the Debate. Labour Economics 30: 43-50.

Helbling, Marc. 2011. Why Swiss-Germans Dislike Germans. European Societies 13(1): 5-27.

Helbling, Marc and Hanspeter Kriesi. 2014. Why Citizens Prefer High- Over Low-Skilled Immigrants: Labor Market Competition, Welfare State, and Deservingness. European Sociological Review 30(5): 595-614.

Hello, Evelyn, Peer Scheepers, and Mérove Gijsberts. 2002. Education and Ethnic Prejudice in Europe: Explanations for Cross-National Variances in the Educational Effect on Ethnic Prejudice. Scandinavian Journal of Educational Research 46(1): 5-24.

Hjerm, Mikael. 1998. National Identities, National Pride and Xenophobia: A Comparison of Four Western Countries. Acta Sociologica 41(4): 335-347.

Iyengar, Shanto, Simon Jackman, Solomon Messing, Nicholas Valentino, Toril Aalberg, Raymond Duch, Kyu S. Hahn, Stuart Soroka, Allison Harell, and Tetsuro Kobayashi. 2013. Do Attitudes About Immigration Predict Willingness to Admit Individual Immigrants? A Cross-National Test of the Person-Positivity Bias. Public Opinion Quarterly 77(3): 641-665.

Lewin-Epstein, Noah, and Asaf Levanon. 2005. National Identity and Xenophobia in an Ethnically Divided Society. International Journal on Multicultural Societies 7(2): 90-118.

Malhotra, Neil, Yotam Margalit, and Cecilia Hyunjung Mo. 2013. Economic Explanations for Opposition to Immigration: Distinguishing Between Prevalence and Conditional Impact. American Journal of Political Science 57(2): 391-410.

Manevska, Katerina and Peter Achterberg. 2013. Immigration and Perceived Ethnic Threat: Cultural Capital and Economic Explanations. European Sociological Review 29(3): 437-449.

Mayda, Anna Maria. 2006. Who Is Against Immigration? A Cross-Country Investigation of Individual Attitudes Toward Immigrants. Review of Economics and Statistics 88(3): 510-530.

Meuleman, Bart, Eldad Davidov, and Jaak Billiet. 2009. Changing Attitudes Toward Immigration in Europe, 2002-2007: A Dynamic Group Conflict Theory Approach. Social Science Research 38(2): 352-365.

O’Connell, Michael. 2011. How Do High-Skilled Natives View High-Skilled Immigrants? A Test of Trade Theory Predictions. European Journal of Political Economy 27(2): 230-240.

Pottie-Sherman, Yolande and Rima Wilkes. 2017. Does Size Really Matter? On the Relationship Between Immigrant Group Size and Anti-Immigrant Prejudice. International Migration Review Early View 51(1): 218-250.

Quillian, Lincoln. 1995. Prejudice as a Response to Perceived Group Threat: Population Composition and Anti-Immigrant and Racial Prejudice in Europe. American Sociological Review 60(4): 586-611.

Scheve, Kenneth F. and Matthew J. Slaughter. 2001. Labor Market Competition and Individual Preferences Over Immigration Policy. Review of Economics and Statistics 83(1): 133-145. 
Schmidt-Catran, Alexander W. and Dennis C. Spies. 2016. Immigration and Welfare Support in Germany. American Sociological Review 81(2): 242-261.

Sciarini, Pascal, Alessandro Nai, and Anke Tresch. 2014. Analyse der eidgenössischen Abstimmungen vom 9. Februar 2014. VOX Analysen eidgenössischer Urnengänge. Bern/Geneva.

Semyonov, Moshe, Rebeca Raijman, and Anastasia Gorodzeisky. 2006. The Rise of Anti-Foreigner Sentiment in European Societies, 1988-2000. American Sociological Review 71(3): 426-449.

Sides, John and Jack Citrin. 2007. European Opinion About Immigration: The Role of Identities, Interests and Information. British Journal of Political Science 37(3): 477-504.

Sniderman, Paul M., Louk Hagendoorn, and Markus Prior. 2004. Predisposing Factors and Situational Triggers: Exclusionary Reactions to Immigrant Minorities. American Political Science Review 98(1): 35-49.

Spies, Dennis C. and Alexander Schmidt-Catran. 2016. Migration, Migrant Integration and Support for Social Spending: The Case of Switzerland. Journal of European Social Policy 26(1): 32-47.

Theiler, Tobias. 2004. The Origins of Euroscepticism in German-Speaking Switzerland. European Journal of Political Research 43(4): 635-656.

Wagner, Ulrich, Rolf van Dick, Thomas F. Pettigrew, and Oliver Christ. 2003. Ethnic Prejudice in East and West Germany: The Explanatory Power of Intergroup Contact. Group Processes and Intergroup Relations 6(1): 22-36.

Weins, Cornelia. 2011. Gruppenbedrohung oder Kontakt? Ausländeranteile, Arbeitslosigkeit und Vorurteile in Deutschland. Kölner Zeitschrift für Soziologie und Sozialpsychologie 63(3): 481-499.

Zamora-Kapoor, Anna, Petar Kovincic, and Charles Causey. 2013. Anti-Foreigner Sentiment: State of the Art. Sociology Compass 7(4): 303-314.

Zárate, Michael A., Berenice Garcia, Azenett A. Garza, and Robert T. Hitlan. 2004. Cultural Threat and Perceived Realistic Group Conflict as Dual Predictors of Prejudice. Journal of Experimental Social Psychology 40(1): 99-105.

\section{$8 \quad$ Appendix}

Table A1

OLS regressions of support for immigration control (seven-point response scale) on vignette variables and respondents' education level and national pride

\begin{tabular}{l|c|c|c}
\hline $\begin{array}{l}\text { Models } \\
\text { Variables }\end{array}$ & $\begin{array}{c}\text { Model (1) } \\
\text { vignette variables only }\end{array}$ & $\begin{array}{c}\text { Model (2) } \\
\text { plus respondents' } \\
\text { education level }\end{array}$ & $\begin{array}{c}\text { Model (3) } \\
\text { plus respondents' } \\
\text { national pride }\end{array}$ \\
\hline $\begin{array}{l}\text { Vignette dimensions (migrant groups) } \\
\text { Nationality of origin (ref.: German) }\end{array}$ & & & \\
French & 0.0391 & 0.0546 & 0.00106 \\
Italian & $(0.104)$ & $(0.106)$ & $(0.102)$ \\
Norwegian & -0.0908 & -0.0678 & -0.0822 \\
Romanian & $(0.100)$ & $(0.102)$ & $(0.0995)$ \\
Croatian & -0.0454 & -0.0527 & -0.0639 \\
& $(0.0931)$ & $(0.0948)$ & $(0.0924)$ \\
& $0.696^{* * *}$ & $0.732^{* * *}$ & $0.739^{* * *}$ \\
& $(0.0980)$ & $(0.0999)$ & $(0.0964)$ \\
& $0.487^{* * *}$ & $0.461 * * *$ & $0.502^{* * *}$ \\
& $(0.105)$ & $(0.107)$ & $(0.104)$
\end{tabular}


Continuation of table $A 1$.

\begin{tabular}{|c|c|c|c|}
\hline $\begin{array}{l}\text { Models } \\
\text { Variables }\end{array}$ & $\begin{array}{c}\text { Model (1) } \\
\text { vignette variables only }\end{array}$ & $\begin{array}{c}\text { Model (2) } \\
\text { plus respondents' } \\
\text { education level }\end{array}$ & $\begin{array}{c}\text { Model (3) } \\
\text { plus respondents' } \\
\text { national pride }\end{array}$ \\
\hline $\begin{array}{l}\text { Education (ref.: university degree) } \\
\text { regular school degree only }\end{array}$ & $\begin{array}{l}0.335^{* * *} \\
(0.0556)\end{array}$ & $\begin{array}{l}0.364^{* * *} \\
(0.0556)\end{array}$ & $\begin{array}{l}0.299 * * * \\
(0.0556)\end{array}$ \\
\hline \multicolumn{4}{|l|}{ Intention to stay (ref.: permanently) } \\
\hline $\begin{array}{l}\text { several years } \\
\text { one year }\end{array}$ & $\begin{array}{c}0.0480 \\
(0.0677) \\
-0.0534 \\
(0.0723)\end{array}$ & $\begin{array}{c}0.0562 \\
(0.0689) \\
-0.0619 \\
(0.0733)\end{array}$ & $\begin{array}{c}0.0891 \\
(0.0675) \\
-0.0389 \\
(0.0712)\end{array}$ \\
\hline \multicolumn{4}{|l|}{$\begin{array}{l}\text { Labour market competition } \\
\text { (ref.: no Swiss people available) }\end{array}$} \\
\hline job for which Swiss people are available & $\begin{array}{l}0.688^{* * *} \\
(0.0620)\end{array}$ & $\begin{array}{l}0.700 * * * \\
(0.0638)\end{array}$ & $\begin{array}{l}0.682^{* * *} \\
(0.0616)\end{array}$ \\
\hline \multicolumn{4}{|l|}{ German language skills (ref.: none) } \\
\hline German language skills & $\begin{array}{l}-0.519 * * * \\
(0.0577)\end{array}$ & $\begin{array}{l}-0.528^{* * *} \\
(0.0585)\end{array}$ & $\begin{array}{l}-0.518^{* * *} \\
(0.0570)\end{array}$ \\
\hline \multicolumn{4}{|l|}{ French language skills (ref.: none) } \\
\hline French language skills & $\begin{array}{l}-0.168^{* * *} \\
(0.0574)\end{array}$ & $\begin{array}{l}-0.170^{* * *} \\
(0.0583)\end{array}$ & $\begin{array}{l}-0.178^{* * *} \\
(0.0567)\end{array}$ \\
\hline \multicolumn{4}{|l|}{$\begin{array}{l}\text { Lifestyle information } \\
\text { (ref.: willingness to adapt) }\end{array}$} \\
\hline $\begin{array}{l}\text { want to keep their way of living } \\
\text { no information on the way of living }\end{array}$ & $\begin{array}{l}0.597^{* * *} \\
(0.0736) \\
0.244^{* *} \\
(0.109) \\
\end{array}$ & $\begin{array}{c}0.615^{* * *} \\
(0.0750) \\
0.256^{* *} \\
(0.108) \\
\end{array}$ & $\begin{array}{l}0.583^{* * *} \\
(0.0716) \\
0.223^{* *} \\
(0.107) \\
\end{array}$ \\
\hline \multicolumn{4}{|l|}{ Respondents characteristics } \\
\hline $\begin{array}{l}\text { Education (ref.: low) } \\
\text { education level high }\end{array}$ & & $\begin{array}{l}-0.598^{* * *} \\
(0.103)\end{array}$ & \\
\hline $\begin{array}{l}\text { National pride (ref.: low) } \\
\text { national pride high }\end{array}$ & & & $\begin{array}{l}0.949 * * * \\
(0.0949)\end{array}$ \\
\hline Constant & $\begin{array}{l}3.045^{* * *} \\
(0.115)\end{array}$ & $\begin{array}{l}3.208^{* * *} \\
(0.120)\end{array}$ & $\begin{array}{l}2.632^{* * *} \\
(0.122)\end{array}$ \\
\hline Observations & 4489 & 4293 & 4277 \\
\hline $\mathrm{R}^{2}$ & 0.092 & 0.115 & 0.149 \\
\hline
\end{tabular}

Robust standard errors in parentheses.

${ }^{* * *} p \leq 0.01,{ }^{* *} p \leq 0.05,{ }^{*} p \leq 0.1$. 


\begin{tabular}{|c|c|c|c|c|c|c|c|c|c|c|}
\hline & 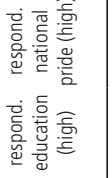 & & & & & & & & $\begin{array}{r}\stackrel{\circ}{\circ} \\
\stackrel{-}{\circ} \stackrel{\circ}{\circ} \\
\stackrel{0}{\circ}\end{array}$ & $\begin{array}{l}\stackrel{\tilde{N}}{0} \\
\frac{\infty}{i} \\
\frac{m}{i}\end{array}$ \\
\hline & 옹 & & & & & & & $\stackrel{8}{\circ}$ & 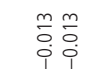 & 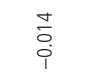 \\
\hline & 을 & & & & & & & 各宲 & $\begin{array}{l}n \\
\text { 응 } \\
0 \\
0\end{array}$ & $\underset{0}{\frac{1}{0}}$ \\
\hline & 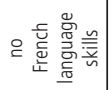 & & & & & & $\stackrel{\circ}{-}$ & 옹 & 홍 & 竎 \\
\hline & 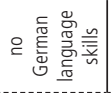 & & & & & $\stackrel{\circ}{\circ}$ & ஜे & ơ & 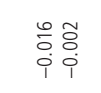 & 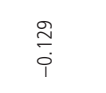 \\
\hline 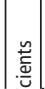 & 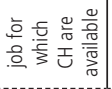 & & & & $\stackrel{\circ}{\circ}$ & $\bar{o}$ & $\begin{array}{l}\circ \\
\stackrel{0}{0} \\
\end{array}$ & 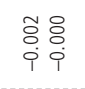 & $\begin{array}{l}0 \simeq \\
00 \\
0 \\
0\end{array}$ & $\frac{8}{\circ}$ \\
\hline 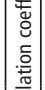 & 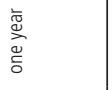 & & & $\stackrel{\circ}{\circ}$ & $\begin{array}{l}\hat{o} \\
\text { i }\end{array}$ & ò & $\begin{array}{l}\text { L } \\
\stackrel{0}{0} \\
\stackrel{i}{1}\end{array}$ & $\begin{array}{l}\text { ợ } \\
\text { o̊ } \\
0\end{array}$ & 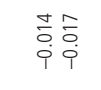 & $\begin{array}{l}\tilde{0} \\
i \\
i\end{array}$ \\
\hline 产 & 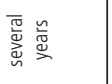 & & & 足 & $\begin{array}{l}\infty \\
\stackrel{0}{+}\end{array}$ & $\begin{array}{l}m \\
0 \\
i\end{array}$ & $\begin{array}{l}m \\
0 \\
0\end{array}$ & 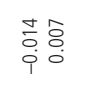 & 용 & $\stackrel{+}{\circ}$ \\
\hline & 흘 & & $\stackrel{\circ}{\circ}$ & 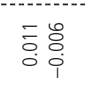 & : & $\begin{array}{l}m \\
\vdots \\
i\end{array}$ & $\begin{array}{l}\tilde{o} \\
\dot{i}\end{array}$ & $\begin{array}{l}\overline{0} \\
\overline{0} \\
0 \\
0 \\
0\end{array}$ & $\begin{array}{l}\text { Iิ } \\
0 \\
0 \\
0\end{array}$ & : \\
\hline & 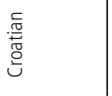 & $\stackrel{\circ}{\circ}$ & $\begin{array}{l}\text { वे } \\
\text { i }\end{array}$ & $\begin{array}{l}\text { o응 } \\
\text { io }\end{array}$ & $\begin{array}{l}\text { ¿े } \\
\text { ¿ } \\
\end{array}$ & 苛 & 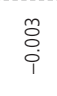 & ố & 응응 & 望 \\
\hline & 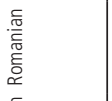 & 条 & $\overline{8}$ & $\begin{array}{l}\text { ò̀ } \\
\text { ọ̆ } \\
\text { ị }\end{array}$ & $\begin{array}{l}m \\
0 \\
0 \\
i\end{array}$ & $\begin{array}{l}0 \\
\vdots \\
i\end{array}$ & ষ̊ & 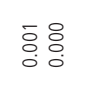 & $\begin{array}{l}\text { 웅음 } \\
0 \\
0\end{array}$ & $\frac{0}{0}$ \\
\hline & 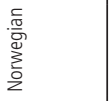 & $\stackrel{\circ}{\circ} \stackrel{\infty}{\circ} \frac{\circ}{i} \frac{\circ}{i}$ & $\begin{array}{l}\text { ò } \\
\text { i }\end{array}$ & 융 & $\begin{array}{l}\overline{8} \\
\bar{i} \\
\end{array}$ & $\overline{8}$ & $\begin{array}{l}\text { Ln } \\
\text { o̊ } \\
\text { i }\end{array}$ & 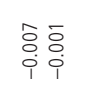 & 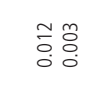 & 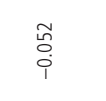 \\
\hline & 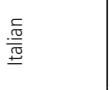 & 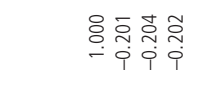 & $\begin{array}{l}\hat{o} \\
\text { i } \\
\text { i }\end{array}$ & $\begin{array}{l}\text { 농영 } \\
\text { ị }\end{array}$ & \%̊. & ò & $\stackrel{n}{\check{c}}$ & 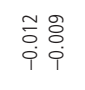 & 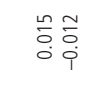 & : \\
\hline & 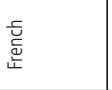 & 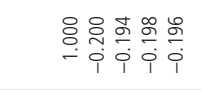 & $\stackrel{\infty}{\circ}$ & ㅁ⿺ㅇ & 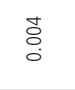 & ఫั & $\stackrel{n}{\circ}$ & 응 & 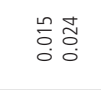 & $\begin{array}{c}\stackrel{\infty}{0} \\
\stackrel{0}{i}\end{array}$ \\
\hline 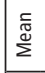 & & 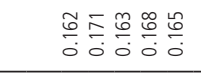 & 奇 & 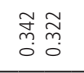 & 商 & 高 & $\begin{array}{l}8 \\
\text { ô } \\
0\end{array}$ & 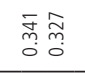 & 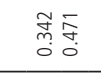 & 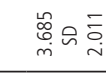 \\
\hline & & 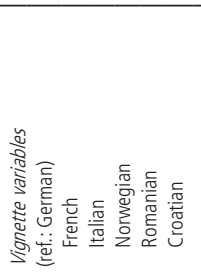 & 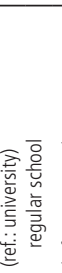 & 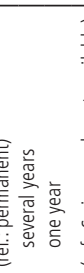 & 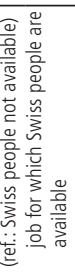 & 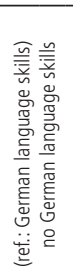 & 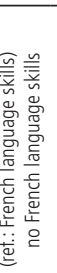 & 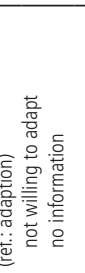 & 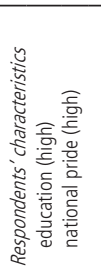 & 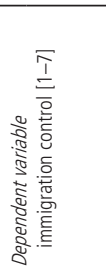 \\
\hline
\end{tabular}

